\title{
A study of effect of a single dose of second generation antihistaminics on cognitive and psychomotor function in healthy human volunteers
}

\author{
Kirti Saxena*, Sachendra K. Srivastava, Chaitali Mehta
}

Department of Pharmacology, Surat Municipal Institute of Medical Education and Research, Surat, Gujarat, India

\author{
Received: 26 September 2020 \\ Revised: 01 November 2020 \\ Accepted: 02 November 2020 \\ *Correspondence: \\ Dr. Kirti Saxena, \\ Email: saxenadrp@gmail.com
}

Copyright: $@$ the author(s), publisher and licensee Medip Academy. This is an open-access article distributed under the terms of the Creative Commons Attribution Non-Commercial License, which permits unrestricted non-commercial use, distribution, and reproduction in any medium, provided the original work is properly cited.

\begin{abstract}
Background: Objective of the study was to assess whether second generation antihistaminic alter psychomotor and cognitive function in comparison with promethazine (marked sedation; altered psychomotor and cognitive impairment). Methods: It was a single blind prospective study. Seventy five healthy human volunteers were registered, divided in five groups. These groups have received placebo, promethazine $25 \mathrm{mg}$, cetirizine $10 \mathrm{mg}$, fexofenadine $120 \mathrm{mg}$ and loratadine $10 \mathrm{mg}$. Cognitive and psychomotor functions were assessed pretreatment and 60 minutes after single dose of drug(post treatment)by using a battery of standard tests (e.g. PST-Perceptual speed test, BVRT-Benton visual retention test,SSS- Stanford Sleepiness Scale, FTT-Finger tapping test etc.). The data were analyzed by student's t-test and ANOVA test.

Results: No significant effect was observed in any test parameter with placebo and fexofenadine. Significant difference with promethazine in PST, BVRT, SSS and cetirizine in DSST, FTT and loratadine in DSST were observed. Significant difference was observed in DSST between the placebo and promethazine, in SSS between promethazine and all other drugs. In FTT and BVRT significant difference between the groups were observed.

Conclusions: Significant sedation and altered cognitive and psychomotor function were observed with promethazine. Cetirizine and loratadine do not cause sedation but both affect psychomotor functions. No significant effect was produced by fexofenadine. Thus, fexofenadine can safely be used in persons involved in activity where alertness is required while cetirizine and loratadine should be avoided.
\end{abstract}

Keywords: Antihistaminic, Cognitive function, Psychomotor function, Sedation

\section{INTRODUCTION}

Antihistaminics (H1 receptors antagonists) are commonly used in various allergic conditions such as conjunctivitis, urticarial, rhinitis, anaphylactic shock, cold remedies, motion sickness etc. ${ }^{1}$

First generation antihistaminics are highly sedative and known to affect the cognitive and psychomotor functions while, second generation antihistaminics are considered as non-sedating and having less effect on psychomotor and cognitive functions. ${ }^{2,3}$ Although second generation antihistaminics considered as safe, less lipid soluble and nonsedating but conflicting reports are available regarding the effect of antihistaminics on CNS functions that include the sedation and effect on cognitive and psychomotor functions. ${ }^{4,5}$ Cetirizine has been shown to produce sedation in highdose. ${ }^{6}$

Assessment of effect of a single dose of second generation antihistaminics on cognitive and psychomotor function is very important for those people in which a little sedation or impairment is caused by a single dose may be dangerous like employee in some critical jobs requiring high level of 
alertness as driver of motor vehicle, pilot of aircraft, machinery operators, students who need full attention at the time of examination, candidate facing some interview for job. ${ }^{4-8}$ A large number of studies have been carried out to assess psychomotor performance and the sedative effect of the $\mathrm{H} 1$ antihistamines. ${ }^{9}$ There are very few studies in Indian population.

This study was therefore carried out to evaluate the effect of a single dose of second generation antihistaminic (fexofenadine, cetirizine, loratadine) in comparison to first generation antihistaminic (promethazine) on cognitive and psychomotor function in normal human volunteers.

Normal healthy human volunteers were chosen because in the patients single dose of antihistaminic is not sufficient to treat the problem, as most of the allergic condition required 5 to 7 days of treatment and so we should not deprive them of treatment as it is irrational to use single dose in patients and our result may alter if patient is on any other medication due to drug- drug interaction.

Also in normal healthy human volunteers only single dose was given to prevent unnecessary exposure to antihistaminics and to prevent the side effects of drugs because antihistaminics can cause many adverse effects or can hamper the normal routine of volunteers.

\section{METHODS}

It was a single blind prospective, case control study done at Surat Municipal Institute of Medical Education and Research Surat Gujarat from May 2015 to January 2016. The clearance from institutional ethical committee was taken. Confidentiality was maintained at all the level. A pilot study was conducted to test feasibility and operational efficiency of certain procedure or unknown effect. 75 healthy human volunteers of both sexes between 18-25 years were registered.

\section{Inclusion criteria}

Healthy human volunteers of both sexes between 18-25 years of age, after taking written informed consent.

\section{Exclusion criteria}

Suffering from any disease or illness, on any medication, gives history of consuming alcohol or tobacco and who had taken caffeinated drink on the day of study were excluded from our study.

Subjects were divided in five groups from A to E (15 subjects in each group). Participants of group A served as control group; that is no antihistaminics was given to them (placebo, Tab. folvite $5 \mathrm{mg}$, wythe). Participants of group B were given first generation antihistaminic, promethazine $25 \mathrm{mg}$ (Tab. avomine $25 \mathrm{mg}$, nicholas piramal) and this group was taken as positive control group. Rests of three groups were given second generation antihistaminics.
Participants of group C were given cetirizine $10 \mathrm{mg}$ (Tab. cetzine $10 \mathrm{mg}$ GSK). Participants of group D were given fexofenadine $120 \mathrm{mg}$ (Tab. allegra $120 \mathrm{mg}$ Sanofi, aventis). Participants of group E were given loratadine 10 $\mathrm{mg}$ (Tab. lorfast $10 \mathrm{mg}$ cipla).

The participants were informed about protocol of study. The written informed consent obtained in proforma prescribed by Institutional Ethics Committee. Cognitive and psychomotor functions of all the subjects from each group were assessed pretreatment and 60 minutes after taking single dose of drug (post treatment), sequence of tests were same as in case of predose. By using a battery of simple tests, which are easy to perform, less time consuming and do not require any complicated instrument. Which are as follows:

\section{Perceptual speed test}

This test measures attention and vigilance as described by Gelfman et al. ${ }^{10}$ In this test subject is required to mark the same digit in the row as the one circled at the beginning of the row in 60 seconds the number of correct responses serves as the score.

\section{Digit symbol substitute test}

It is a test of psychomotor performance in this test the subject is given a key grid of numbers and matching symbols and a test section with numbers and empty boxes. ${ }^{11}$ The test consists of filling as many empty boxes as possible with a symbol matching each number in 90 seconds.

\section{Stanford sleepiness scale}

This is an introspective measure of sleepiness. Subjects were given a printed sheet having a seven point scale mentioning degree of sleepiness and scale rating from 1 to 7.

\section{Forward digit span test}

The participants were instructed to listen carefully as investigator says some numbers and repeat them. Count maximum correct digit span forward until two consecutive failures on same length.

\section{Backward digit span test}

The participants were instructed to listen carefully as investigator says some numbers and repeat themthe participants were instructed tocount maximum correct digit span backward until two consecutive failure on same length.

\section{Trail making tasks A}

Subjects are asked to make trail by connecting numbers and time notedthe participants were instructed to listen 
carefully as investigator says some numbers and repeat them.

\section{Trail making tasks $B$ )}

Subjects are asked to make trail by connecting numbers and alphabets and time noted.

\section{Word memory task}

Subject is asked to listen and repeat list of word as many as possible.

\section{Finger tapping task}

To assess the motor function. Participants were instructed to tap on 'Tab key' of lap top by index finger of dominant hand as rapidly as possible for 30 seconds and duration is noted by using stop watch.

\section{Benton visual retention test}

Participants were shown a card for 10 seconds carrying test image followed by another card having one response image and two distractors same test was repeated with another set of cards one hour after administration of test drugs to assess visual memory.

\section{Statistical analysis}

All mentioned tests were done predose and postdose in each groups and all data was analyzed by using statistical software SPSS-16 version and Microsoft excel 2010. Data was analyzed by applying paired t test, ANOVA test followed by Tukey's post hoc test for all multiple comparisons.

\section{RESULTS}

Total 75 volunteers were registered, among them 26 were male and 49 were female. Mean age of volunteers was $20.46 \pm 1.06$ years. Results were described in table. Significance of difference was analyzed by paired ' $t$ - test' $\mathrm{p}$ value less than 0.05 considered as significant.

\section{Group A effect of placebo}

We observed no statistically significant difference on various test parameters both predose mean and postdose mean with placebo (p value $>0.05$ ) (Table 1$)$.

Table 1: Effect of placebo on various test parameters.

\begin{tabular}{|llllll|}
\hline Tests & Pre-dose mean & Pre-dose SD & Post-dose mean & Post-dose SD & P value \\
\hline PST & 46.33 & 6.15 & 44.2 & 7.29 & 0.14 \\
\hline DSST & 68.27 & 7.12 & 71.53 & 9.05 & 0.061 \\
\hline FDST & 8.8 & 1.01 & 9.2 & 1.08 & 0.054 \\
\hline BDST & 6.87 & 1.77 & 7.4 & 1.3 & 0.164 \\
\hline SSS & 1.6 & 0.63 & 1.67 & 0.72 & 0.582 \\
\hline TMT- A & 22.2 & 7.08 & 22.07 & 9.62 & 0.935 \\
\hline TMT-B & 45.33 & 14.16 & 45.07 & 12.16 & 0.912 \\
\hline WMT-1 & 6.93 & 1.71 & 7.2 & 1.42 & 0.499 \\
\hline WMT-2 & 8.33 & 1.4 & 8.6 & 1.4 & 0.433 \\
\hline FTT & 161.07 & 35.06 & 162.73 & 30.29 & 0.641 \\
\hline BVRT & 4.8 & 0.41 & 5 & 0 & 0.082 \\
\hline
\end{tabular}

Tests (PST, DSST, FDST, BDST, SSS, WMT-I, WMT-2, FTT, BVRT) are expressed as in numbers and Tests TMT-A and TMT-B are expressed as time duration in seconds.

Table 2: Effect of promethazine on various test parameters.

\begin{tabular}{|llllll|}
\hline Tests & Pre-dose mean & Pre-dose SD & Post-dose mean & Post-dose SD & P value \\
\hline PST & 45.33 & 5.05 & 39.73 & 7.35 & $0.013^{*}$ \\
\hline DSST & 63.2 & 8.17 & 60.47 & 9.67 & 0.318 \\
\hline FDST & 8.73 & 1.67 & 8.6 & 1.35 & 0.61 \\
\hline BDST & 7 & 1.96 & 6.93 & 1.98 & 0.879 \\
\hline SSS & 1.8 & 1.01 & 3.47 & 1.73 & $0.001 * *$ \\
\hline TMT- A & 25.2 & 7.75 & 24.33 & 6.82 & 0.65 \\
\hline TMT-B & 51.73 & 14.94 & 50.73 & 11.74 & 0.812 \\
\hline WMT-1 & 6.93 & 1.67 & 6.47 & 1.64 & 0.363 \\
\hline WMT-2 & 8.33 & 1.54 & 8.13 & 1.13 & 0.619 \\
\hline FTT & 133 & 45.38 & 125.4 & 27.84 & 0.474 \\
\hline BVRT & 4.87 & 0.35 & 4.4 & 0.63 & $0.004 * * *$ \\
\hline
\end{tabular}

Test (PST, DSST, FDST, BDST, SSS, WMT-I, WMT-2, FTT, BVRT) are expressed in numbers and Tests TMT-A and TMT-B are express time duration in seconds. (P value $<0.05$ ) for PST, SSS and BVRT). 
Table 3: Difference in the effect of promethazine between female and male on stanford sleepiness scale.

\begin{tabular}{|lllll|} 
& Females & Males & \\
& Pre-dose & $\begin{array}{l}\text { Post- } \\
\text { dose }\end{array}$ & $\begin{array}{l}\text { Pre- } \\
\text { dose }\end{array}$ & Post-dose \\
\hline Mean & 2 & 4.25 & 1.57 & 2.57 \\
\hline SD & 1.195 & 1.982 & 0.787 & 0.787 \\
\hline P value & 0.008 & & 0.061 & \\
\hline
\end{tabular}

\section{Group (B) effect of promethazine}

There was statistically significant difference observed on * perceptual speed test ( $\mathrm{p}$ value $=0.013$ and $\mathrm{t}$-value $=2.845$, 95\% confidence interval 1.378-9.822), ${ }^{*}$ Stanford Sleeping Scale ( $\mathrm{p}$ value 0.001 and $\mathrm{t}$ value- 4.063 , 95\% confidence interval 2.546 to 0.787 ) and $* * * B V R T$ ( $\mathrm{p}$ value $=0.004$ and $\mathrm{t}$ value $=3.5,95 \%$ confidence interval 0.181 to 0.753 ) while no statistically significant effect has been observed in other tests variable $(\mathrm{p}>0.05)$ (Table 2$)$.

Predose and postdose mean of SSS is expressed in number. In female ( $p$ value<0.008) highly significant (Table 3 ).

\section{Group (C) effect of cetirizine}

In group $\mathrm{C}$ there was a statistically significant difference observed in $*$ DSST $(\mathrm{P}$ value $=0.046, \mathrm{t}$ value $=2.84,95 \%$ confidence of interval 0.093 to 10.174 ) and $* *$ FTT (P value 0.001 , $t$ value $4.075,95 \%$ confidence of interval 10.675 to 34.392) while no statistically significant effect was observed in other test variable ( $\mathrm{p}$ value>0.05) (Table 4).

\section{Group (D) effect of fexofenadine}

There was no statistically significant effect was observe in any test parameter (group D) $\mathrm{p}$ value $>0.05$ for all parameters (Table 5).

\section{Group (E) effect of loratadine}

Statistically significant difference in $*$ DSST was observed with loratadine ( $\mathrm{p}$ value $=0.034$, $\mathrm{t}$-value $=2.348,95 \%$ confidence interval range 0.404 to 8.929 ) while no statistically significant effect was been observe in other test variable (p-value>0.05) (Table 6). ANOVA test was done to know any variation in within the group and between the groups for individual test analysis.

Table 4: Effect of cetirizine on various test parameters.

\begin{tabular}{|lll|lll|} 
Test & Pre-dose mean & Pre-dose SD & Post-dose mean & Post-dose SD & P value \\
\hline PST & 46 & 6.44 & 43.2 & 7.35 & 0.12 \\
\hline DSST & 67.2 & 10.06 & 62.07 & 11.23 & $* \mathbf{0 . 0 4 6}$ \\
\hline FDST & 9.13 & 1.06 & 9.27 & 1.03 & 0.546 \\
\hline BDST & 7.47 & 1.46 & 7.93 & 1.83 & 0.169 \\
\hline SSS & 1.6 & 0.63 & 1.53 & 0.64 & 0.774 \\
\hline TMT- A & 23.67 & 7.67 & 22.33 & 3.33 & 0.462 \\
\hline TMT-B & 54.73 & 9.48 & 51.2 & 10.24 & 0.22 \\
\hline WMT-1 & 6.8 & 1.42 & 7.27 & 1.44 & 0.204 \\
\hline WMT-2 & 8.4 & 1.35 & 8.33 & 1.11 & 0.872 \\
\hline FTT & 163.27 & 37.94 & 140.73 & 41.82 & $* * \mathbf{0 0 1}$ \\
\hline BVRT & 4.8 & 0.41 & 4.87 & 0.52 & 0.719 \\
\hline
\end{tabular}

Test (PST, DSST, FDST, BDST, SSS, WMT-1, WMT-2, FTT, BVRT) scores are expressed as numbers and Tests TMT-A and TMT-B are expressed time duration in seconds. For DSST and FTT ( $\mathrm{p}$ value $<0.05$ using paired' $t$ test')

Table 5: Effect of fexofenadine on various test parameters.

\begin{tabular}{|llllll|}
\hline Test & Pre-dose mean & Pre-dose SD & Post-dose mean & Post-dose SD & P value \\
\hline PST & 45.4 & 5.93 & 42.93 & 6.71 & 0.08 \\
\hline DSST & 62 & 9.008 & 64 & 8.619 & 0.39 \\
\hline FDST & 9.733 & 0.594 & 9.667 & 0.488 & 0.582 \\
\hline BDST & 8.333 & 1.234 & 8.667 & 1.543 & 0.43 \\
\hline SSS & 1.267 & 0.594 & 1.467 & 0.64 & 0.334 \\
\hline TMT- A & 22.667 & 4.909 & 22 & 5.332 & 0.585 \\
\hline TMT-B & 54.333 & 8.756 & 51.8 & 7.683 & 0.416 \\
\hline WMT-1 & 7.067 & 1.033 & 7.2 & 1.146 & 0.546 \\
\hline WMT-2 & 9 & 0.926 & 8.867 & 1.246 & 0.737 \\
\hline FTT & 169 & 23.746 & 172.533 & 17.25 & 0.564 \\
\hline BVRT & 4.6 & 0.828 & 4.933 & 0.258 & 0.173 \\
\hline
\end{tabular}

Test (PST, DSST, FDST, BDST, SSS, WMT-I, WMT-2, FTT, BVRT) are express in numbers and Tests TMT-A and TMT-B are express time duration in seconds ( $\mathrm{p}$ value $>0.05$ ) for all tests parameters. 
Table 6: Effect of loratadine on various test parameters.

\begin{tabular}{|llllll|} 
Test & Pre-dose mean & Pre-dose SD & Post-dose mean & Post-dose SD & P value \\
\hline PST & 45.2 & 9.03 & 42.8 & 6.43 & 0.18 \\
\hline DSST & 64.73 & 11.74 & 60.07 & 7.12 & $* \mathbf{0 . 0 3 4}$ \\
\hline FDST & 9.6 & 0.91 & 9.4 & 1.24 & 0.51 \\
\hline BDST & 8.27 & 1.75 & 8.13 & 1.92 & 0.737 \\
\hline SSS & 1.67 & 0.62 & 1.87 & 0.83 & 0.334 \\
\hline TMT- A & 20 & 3.89 & 20.2 & 3.9 & 0.874 \\
\hline TMT-B & 45.13 & 9.94 & 48.6 & 10.03 & 0.181 \\
\hline WMT-1 & 7 & 1.81 & 7.47 & 1.81 & 0.396 \\
\hline WMT-2 & 8.6 & 1.45 & 9.13 & 1.19 & 0.056 \\
\hline FTT & 130.67 & 49.99 & 153.27 & 0.41 & 0.089 \\
\hline BVRT & 4.4 & 0.91 & 4.8 & 0.47 & 0.111 \\
\hline
\end{tabular}

Test (PST, DSST, FDST, BDST, SSS, WMT-I, WMT-2, FTT, BVRT) are express in numbers and Tests TMT-A and TMT-B are express time duration in seconds.

Table 7: P-value of all tested drugs on various test parameters.

\begin{tabular}{|llllll|} 
Tests & Placebo & Promethazine & Cetirizine & Fexofenadine & Loratadine \\
\hline PST & 0.14 & 0.013 & 0.12 & 0.08 & 0.18 \\
\hline DSST & 0.061 & 0.318 & 0.046 & 0.39 & 0.034 \\
\hline FDST & 0.054 & 0.61 & 0.546 & 0.582 & 0.51 \\
\hline SSS & 0.164 & 0.879 & 0.169 & 0.43 & 0.737 \\
\hline TMT-A & 0.582 & 0.001 & 0.774 & 0.334 & 0.334 \\
\hline TMT-B & 0.935 & 0.65 & 0.462 & 0.585 & 0.874 \\
\hline WMT-1 & 0.499 & 0.363 & 0.22 & 0.416 & 0.181 \\
\hline WMT-2 & 0.433 & 0.619 & 0.204 & 0.546 & 0.396 \\
\hline FTT & 0.641 & 0.474 & 0.872 & 0.737 & 0.056 \\
\hline
\end{tabular}

Table 8: Post hoc analysis of effect of antihistaminics on post dose DSST.

\begin{tabular}{|ll|}
\hline Groups & P value \\
\hline Promethazine and placebo & 0.01 \\
\hline Promethazine and cetirizine & 0.988 \\
\hline Promethazine and fexofenadine & 0.816 \\
\hline Promethazine and loratadine & 1 \\
\hline
\end{tabular}

( $\mathrm{p}$ value $<0.05$ ) in between promethazine and placebo.

When variation in amongst the antihistaminics was compared in PST, FDST, BDST, TMT-A, TMT-B, WML1and WML-2. There was no statistically significant variation between the groups and within the groups, (pvalue>0.05). DSST- When variation in amongst the antihistaminics in DSST was compared there was statistically significant difference in between the groups and within group ( $\mathrm{p}$ value $=0.005, \mathrm{~F}$ value=4.096). After application of post hoc test for multiple variable comparisons we observed there was significant variation between placebo, promethazine, cetirizine and loratadine (Table 8).

SSS- on comparison of variation amongst the antihistaminics in Standford sleepiness scale we observed that there was statistically significant difference in between groupand within group ( $\mathrm{p}$ value $=0.000$ and $\mathrm{F}$ value $=$ 10.394) (Figure 1). Results are expressed as Mean \pm SD. FTT- On comparison of variation amongst the antihistaminics in FTT there was statistically significant difference was observed between the groups and within the groups $(\mathrm{p}$ value $=0.001, \mathrm{~F}$ value $=5.348)$.

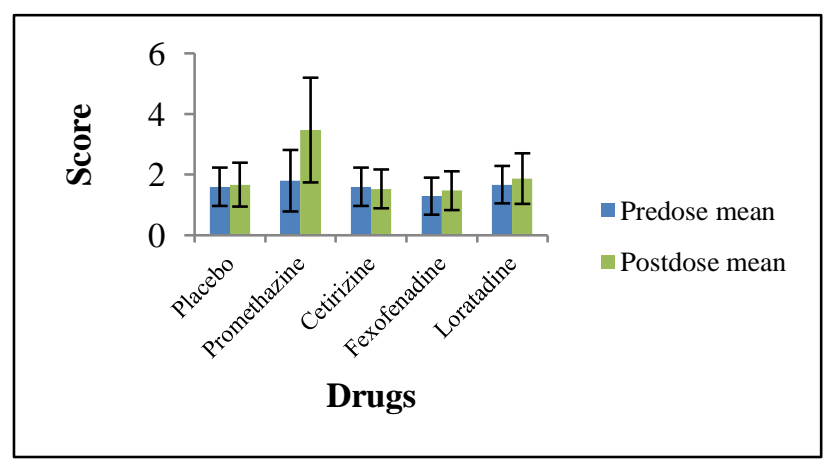

Figure 1: Comparison of variation in SSS amongst the antihistaminics.

After application of post hoc test on FTT, we observed there was statically significant variation between placebo and promethazine, cetirizine and fexofenadine and highly 
significant variation is seen when we compared fexofenadine and promethazine ( $\mathrm{p}$ value $=0.001)($ Table 9$)$.

Table 9: Post hoc analysis of effect of antihistaminics on FTT.

\begin{tabular}{|ll|}
\hline Groups & P value \\
\hline Promethazine and placebo & 0.013 \\
\hline Promethazine and cetirizine & 0.657 \\
\hline Promethazine and fexofenadine & 0.001 \\
\hline Promethazine and loratadine & 0.111 \\
\hline FTT expressed in numbers. &
\end{tabular}

BVRT- when we compared the variation amongst the antihistaminics in BVRT there was statistically significant difference in between group and inter groups ( $p$ value $=0.002, F$ value $=4.605$ ). Highly significant difference observed in placebo and promethazine $(p$-value $=0.002)$ (Table 10).

Table 10: Post hoc analysis of effect of antihistaminics on BVRT.

\begin{tabular}{|l|l|}
\hline Groups & P value \\
\hline Promethazine and placebo & 0.002 \\
\hline Promethazine and cetirizine & 0.029 \\
\hline $\begin{array}{l}\text { Promethazine and } \\
\text { fexofenadine }\end{array}$ & 0.009 \\
\hline Promethazine and loratadine & 0.086 \\
\hline
\end{tabular}

BVRT scores are expressed in numbers.

\section{DISCUSSION}

In our study in promethazine group (positive control) there was significant change in PST, Stanford Sleepiness Scale and BVRT (p-value<0.05) while there was no significant effect is seen in other parameters but in the study by Hindmarch et al promethazine taken as positive control group showed significantly reduced Critical flicker fusion threshold (CFFT). ${ }^{12}$ David et al observed promethazine significantly decrease in finger tapping count (FT) and Critical flicker fusion threshold (CFFT) observed $(\mathrm{p}<0.001)$ as compared to control group which demonstrated decline in cognitive functions. ${ }^{13}$ Jauregui et al observed that classic antihistamines increased day time sleepiness and decreased the sleep quality scores. ${ }^{14}$

Kamei et al concluded that fexofenadine did not cause any cognitive or psychomotor dysfunction when administered at the therapeutic doses, in contrast to the sedative effect of promethazine ( $\mathrm{p}$ value $<0.05$ ), Rapid Visual Information Processing test (RVIP) also done to assess attention performance and it was observed that promethazine significantly decreases correct response. ${ }^{15}$ Promethazine is potent histamine and acetylcholine receptor antagonist that is why having more sedative effect in comparison with second generation antihistaminics.

Valk et al studied the adverse effects of $\mathrm{H} 1$ antihistaminics (mainly first generation) can interfere with the performance of daytime activities and place the patient at risk of accidents in situations such as driving and operation of machinery.?

Church et al studied effects of first-generation $\mathrm{H} 1$ antihistamines on the CNS are similar to and additive with those produced by ethanol or other CNS-sedatives, such as benzodiazepines. ${ }^{16}$ Sen et al examined The Civil Aerospace Medical Institute's (CAMI's) Toxicology database for the presence of the first-generation antihistamines in pilot fatalities of civil aircraft accidents that occurred during a 16-year (1990-2005) period. ${ }^{17}$

In our study we observed that cetrizine significantly affects DSST and FTT (p value $<0.05$ and 0.001 respectively). Gango et al also observed change in DSST and Trail making task B (TMT B). ${ }^{18}$

Hindmarch et al observed that cetrizine does not cause any change in DSST and do not affect SSS which is different from our study. They also observed and does not make any significant change in simple reaction task (SRT) score. ${ }^{12}$

In study by Gupta et al it was observed that $10 \mathrm{mg}$ of cetrizine produced significant degree of sedation but do not affect DSST and digit cancellation test (DCT). ${ }^{19}$ These finding are similar with study of Tashiro et al. ${ }^{3}$ However Gango et al and Simons observed that cetrizine is nonsedating antihistaminic. ${ }^{18,20}$ Kamei et al revealed that cetrizine penetrate brain may result in dose related cognitive impairment. ${ }^{15}$ Gupta et al observed that Cetrizine and Fexofenadine not alter the DSST which is similar in our study with Fexofenadine but cetrizine shows significant effect on DSST (p value-0.004). ${ }^{19}$

We observed no change in any parameter with fexofenadine which is similar with placebo. Hindmarch et al showed that fexofenadine does not affects psychomotor function and causes sedation even in high dose up to $180 \mathrm{mg} .{ }^{12}$ Gupta et al was observed that fexofenadine do not interfere with psychomotor functions and fine skills; finding of these two studies are similar to our study. Same result seen in other study done by Bender et al. ${ }^{19,21}$

Kamel et al also found same results and no effect on psychomotor functions but David et al observed that fexofenadine causes a decrease in DSST, FT count and causes sedation. ${ }^{13,15}$ The findings of study of Gupta et al were also similar with study of Vermeen and O'Hanlon. ${ }^{19,22}$ In present study no significant change observed in finger tapping. Other study done by David et al observed that fexofenadine decrease finger tapping count. ${ }^{13}$ In our study we observed significant change in DSST with loratadine ( $\mathrm{p}$ value $=0.03$ ) while there was no change in other parameters but in study done by David et al an increased in finger tapping count was observed but no change in DSST was observed. Both of the studies concluded that loratidine is non-sedating antihistaminic. David et al observe loratadine was only antihistaminic which affects the psychomotor functions but does not cause 
sedation. Loratadine does not alter the performance at therapeutic doses of $10 \mathrm{mg} /$ day that all antihistaminics causes sedation except loratidine and second generation antihistaminics also affects psychomotor functions in Indian population. ${ }^{13}$

In study done by Hindmarch et al loratidine is taken as negative internal control and promethazine as positive controlled they used CFFT, choice reaction time (CRT), line analogue rating scale for sedation and noted that it is a non- sedative antihistaminic and does not cause CNS side effects following $10 \mathrm{mg}$ dose. ${ }^{12}$

Valk et al concluded that loratadine is similar to placebo in effects on daytime somnolence and psychomotor performance. Loratadine treatment resulted in significantly less sleepiness and impairment of vigilance and tracking than diphenhydramine. ${ }^{10}$

Small sample size was the limitation and the finding needs further confirmation by investigation on large population and second generation antihistaminics. Further patients were not included in the study because single dose cannot be given to the patient as they will be deprived of treatment. In present study only three second generation antihistaminics (cetirizine, fexofanadine and loratadine) were included.

\section{CONCLUSION}

Second generation antihistaminics are supposed to be nonsedating however they may cause sedation, some studied have shown alteration in psychomotor function by second generation antihistaminics, so these drugs are unsafe and even single dose may be hazardous in subjects whose job requires alertness.

Our study has confirmed the sedative effect of promethazine and alteration in cognitive and psychomotor function. Cetirizine and loratadine with a single dose there was no sedation but they alter the some parameter of psychomotor function. Cetirizine altered the DSST and FTT score. Loratadine altered the DSST only.

On the contrary, the fexofenadine did not produced sedation and no effect on any cognitive and psychomotor functions. Thus, based on the present study it may be concluded that cetirizine and loratadine should not be used by the person performing the job that requires alertness, such as driving vehicles and machinery, while fexofenadine can safely be used.

Funding: No funding sources Conflict of interest: None declared

Ethical approval: The study was approved by the Institutional Ethics Committee

\section{REFERENCES}

1. Brunton LL, editor. Goodman and Gillman's The Phramacological Basis of Therapeutics. McGraw Hill Education. 12 $2^{\text {th }}$ edition. 2017.

2. Okamura N, Yanai K, Higuchi M, Sakai J, Iwata R, Ido $\mathrm{T}$, et al. Functional neuroimaging of cognition impaired by a classical antihistamine, dchlorpheniramine. Br J Pharmacol. 2000;129(1):11523.

3. Tashiro M, Sakurada Y, Iwabuchi K, Mochizuki H, Kato M, Aoki M, et al. Central effects of fexofenadine and cetirizine: measurement of psychomotor performance, subjective sleepiness, andbrain histamine H1-receptor occupancy using C-11 doxepin positron emission tomography. J Clin Pharmacol. 2004;44:890-900.

4. $\mathrm{Br} \mathrm{A}$. Sedation and performance issues in the treatment of allergic conditions. Arch Intern Med. 1997;157(5):494-500.

5. Mann RD, Pearce GL, Dunn N, Shakir S. Sedation with "non-sedating" antihistamines: four prescriptionevent monitoring studies in general practice. Brit Med J. 2000;320(7243):1184-6.

6. Tashiro M, Kato M, Miyake M, Watanuki S, Funaki $\mathrm{Y}$, Ishikawa $\mathrm{Y}$, et al. Dose dependency of brain histamine $\mathrm{H} 1$ receptor occupancy following oral administration of cetirizine hydrochloride measured using PET with [11C] doxepin. Hum Psychopharmacol Clin Exp. 2009;24:540-8.

7. Valk PJ, Simons M. Effects of loratadine/montelukast on vigilance and alertness task performance in a simulated cabin environment. Adv Ther. 2009;26(1):89-98.

8. Ozdemir PG, Karadag AS, Selvi Y, Boysan M, Bilgili SG, Aydin A, et al. Assessment of the effects of antihistamine drugs on mood, sleep quality, sleepiness, and dream anxiety. Int J Psychiatry Clin Pract. 2014;18(3):161-8.

9. Soper JW, Chaturvedi AK, Canfield DV. Prevalence of chlorpheniramine in aviation accident pilot fatalities, 1991-1996. Oklahoma: Civil Aeromedical Institute, Federal Aviation Administration, Oklahoma; 1999. Report No.: ADA372538.

10. Wechsler adult intelligence scale revised. Available at https://link.springer.com/chapter/10.1007/978-14757-3224-5_6. Accessed on 12 June 2020.

11. Matarazzo JD, Herman DO. Base rate data for the WAIS-R: test-retest stability and VIQ-PIQ differences. J Clin Neuropsychol. 1984;6:351-66.

12. Hindmarch I, Shamsi Z, Kimber S. An evaluation of the effects of high-dose fexofenadine on the central nervous system: a double-blind, placebo-controlled study in healthy volunteers. Clin Exp Allergy. 2002;32(1):133-9.

13. David VK, Badyal DK, Varghese A, Alexander E. Comparative effect of newer antihistamines on psychomotor functions in Indian population. $\mathrm{J} \mathrm{K}$ Science. 2010;12(1):15-8. 
14. Jáuregui I, Mullol J, Bartra J, Cuvillo D, Dávila I, Montoro J, et al. H1 antihistamines: psychomotor performance and driving. J Investig Allergol Clin Immunol. 2006;16(1):37-44.

15. Kamei H, Isaji A, Noda Y, Ishikawa K, Senzaki K, Yamada K, et al. Effects of single therapeutic doses of promethazine, fexofenadine and olopatadine on psychomotor function and histamine-induced whealand flare-responses: a randomized double-blind, placebo-controlled study in healthy volunteers. Arch Dermatol Res. 2012;304(4):263-72.

16. Church MK, Maurer M, Simons FE, Jensen C, Cauwenberge P, Bousquet $\mathrm{J}$, et al. Risk of firstgeneration $\mathrm{H}(1)$-antihistamines: a $\mathrm{GA}(2) \mathrm{LEN}$ position paper. Allergy. 2010;65(4):459-66.

17. Sen A, Akin A, Craft KJ, Canfield DV, Chaturvedi AK. First-generation $\mathrm{H} 1$ antihistamines found in pilot fatalities of civil aviation accidents, 1990-2005. Aviat Space Environ Med. 2007;78(5):514-22.

18. Gengo FM, Gabos C, Mechler L. Quantitative effects of cetirizine and diphenhydramine on mental performance measured using an automobile driving simulator. Ann Allergy. 1990;64:520-6.

19. Gupta S, Kapoor B, Gillani Z, Kapoor V, Gupta BM. Effects of fexofenadine, cetirizine and diphenhydramine on psychomotor performance in adult healthy volunteer. J K Science. 2004;6(4):201-5.

20. Simons FE, Fraser TG, Simons KJ, Reggin JD. Individual differences in central nervous system response to antihistamines (H1-receptor antagonists). Ann Allergy Asthma Immunol. 1995;75(6):507-14.

21. Bender BG, Berning S, Dudden R, Milgrom H, Tran $\mathrm{ZV}$. Sedation and performance impairment of diphenhydramine and second-generation antihistamines: a meta-analysis. J Allergy Clin Immunol. 2003;111(4):770-6.

22. Vermeeren A, O'Hanlon JF. Fexofenadine's effects, alone and with alcohol, on actual driving and psychomotor performance. J Allergy Clin Immunol. 1998;101:306-11.

23. Valk PJ, Simons M. Effects of loratadine/montelukast on vigilance and alertness task performance in a simulated cabin environment. Adv Ther. 2009;26(1):89-98.

Cite this article as: Saxena $\mathrm{K}$, Srivastava SK, Mehta C. A study of effect of a single dose of second generation antihistaminics on cognitive and psychomotor function in healthy human volunteers. Int J Basic Clin Pharmacol 2020;9:1836-43. 